\title{
Using a Brand Identity-Focused Project Structure to Improve the Competencies of Product Design Students
}

\author{
Bulent Unal (1) \\ Attlim University, Ankara, Turkey \\ H. Merve Demirci \\ Atılim University, Ankara, Turkey \\ Middle East Technical University, Ankara, Turkey \\ Emrah Demirhan \\ Attlim University, Ankara, Turkey
}

Received: October 22nd 2021, Revised: December 10th 2021, Accepted: December 13th 2021.

Refer: Unal, B., Demirci, H.M., Demirhan, E., (2021), Using a Brand Identity-Focused Project Structure to Improve the Competencies of Product Design Students, Journal of Design Studio, V.3, N.2, pp 191-203,

B. Unal ORCID: 0000-0003-1721-7903, H.M. Demirci ORCID: 0000-0002-0315-5898, E. Demirhan ORCID: 0000-0001-8851-7765 DOI: $10.46474 /$ jds.1013343 https://doi.org/10.46474/jds.1013343

\begin{abstract}
It is essential to reflect the strategic connotations of the brand on the products while creating and developing a product design that fits the brand identity. Therefore, for a company, it is a critical issue to place the right messages that support the strategic brand identity in the design elements. From the designers' point of view, they are expected to have design skills such as analyzing a brand's uniqueness and brand knowledge and reflecting the results of these analyses on the aesthetics, function and overall meaning of the product. For this reason, as a part of the Industrial Design curriculum, brand identity focused product design has been restructured in Attlim University, Industrial Design program. In this studio course, the aim was for design students to acquire skills of brand identity and product identity analysis, in addition to basic design knowledge and skills. During 16 weeks, the data were collected by doing a participant observation and conducting semi-structured interviews with the course students. The data gathered from the semi-structured interviews and participant observation were analysed by using an inductive coding approach. Thus, product design suggestions that were suitable for the identity of the brand were analysed with the questions asked by the instructors during the design process. The results show that the questions asked by the instructors and the examples they gave, led the students to research, think, question, understand and make sense of the importance of information. As a result, the students obtained design outputs suitable for brand identity.
\end{abstract}

Keywords: Design Education, Product Design Education, Product Design, Brand Identity, Analysis of Brand Identity

\section{Introduction}

The semantic dimension of product design is becoming more critical in advanced product categories where technical differences between products are diminishing. Product design also shifts towards communicative product attributes that represent the symbolic domain of the product (Karjalainen, 2003a; Stompff, 2010). In other words, product design can be used as a manifestation of brand identity.

Placing strategic associations in products is essential when creating and developing product design that fits the brand identity (Karjalainen, 2003b). Brand identity-specific 
product design can be regarded as the intersection of product semantics and brand research. In advanced product categories, where technical differences between products are reduced, the focus shifts to communicative product attributes representing the product's symbolic domain (Karjalainen, 2003a). In other words, communicative qualities are often intertwined with a specific set of meanings that refer to the brand represented by the product (Homburg, Schwemmle, \& Kuehnl, 2015). Therefore, for a company, it is a crucial issue to place the right messages that support the strategic brand identity in the design elements.

Numerous research results (Greenberg et al., 2020; Heitmann et al., 2020; Homburg et al., 2015; Kreuzbauer and Malter, 2007; Stompff, 2010; Wang et al., 2008) show that as competition becomes more intense than ever, product design becomes increasingly important to firms. It has become an essential strategic tool that they can use to gain a sustainable competitive advantage (Page and Herr, 2002). However, the aesthetic forms of products are not the only factors that affect consumers' product perception and purchasing decisions (Heitmann et al., 2020; Homburg et al., 2015). In addition to the forms of the products, the functionality and symbolism dimensions of the product design also have a decisive effect on the differentiation of products from their counterparts (Homburg et al., 2015).

From the designers' point of view, designing products that align with the brand's strategically defined message requires specific product knowledge (Warell, 2015). This is the recognition and identification of specific brand identity references in product design, in other words, the analysis of brand-specific design language and the reflection of the three dimensions of product design, aesthetics, functionality and symbolism, to design (Warell, 2015; Maurya and Mishra, 2012). Therefore, to transfer meaning through product design, product designers must place an association reference in the products they design and recognize and define the identity of the brand's products (Slade-Brooking, 2016; Warell, 2015; Karjalainen, 2003b).
Product designers working in the industry are expected to analyze a brand's uniqueness and brand information to reveal visually consistent designs in product design processes and to have design skills such as reflecting the results of these analyses to the aesthetic, function and semiotic meaning of the product (Naletelich and Spears, 2020). During their education, design students try to acquire skills such as brand identity analysis, product identity analysis, corporate identity creation, and basic design knowledge and skills to design outstanding products for their companies. These knowledge and skills have to be the skills that designers learn during undergraduate design education. For this reason, as a part of the Industrial Design education curriculum, brand identity focused product design has been restructured in At1lim University Industrial Design program with the process models applied in product design studio courses.

The need to align product design studio training with the skills required to design products that reflect brand identity relates to the process models applied in structuring product design studio courses. The design process in the studio was 14 weeks of consecutive brand and product identity analysis that is structured to focus on visuality, aesthetic perception, functionality and symbolism. The course instructors foresaw that the design of brand identity-oriented products might require a different approach in terms of product design studio training, and preparing product design students for the future was questioned in the focus of product design education throughout the semester.

This article will first review the literature describing strategies/methods for training product design students to analyze/reflect brand identity. Then, a different project setup applied in the third year product design studio course; product design for a selected science fiction film, product design for a brand assigned to each student, which is not included in the product range of the brand, and product family design specific to the same brand. Finally, the research findings are shared with comments and possible implications for 
product design education. The study concludes with an indication of potential areas for further research.

\section{Product Design Education and Design Studio Projects}

In the curriculum of the Attlim University Department of Industrial Design, the design studio courses are accompanied by compulsory courses that provide students with detailed theoretical and technical knowledge and skills. In the product design curriculum, there are must courses regarding visualization and modelling techniques, including freehand drawing techniques, technical drawing, model making and computer-aided 3D modelling; and materials knowledge, production techniques, ergonomics, user research, marketing, design management, design history, and cultural and critical aspects of design. The design education curriculum also includes a wide range of practical and theory-based area electives that offer specific skills, knowledge and experience.

Design studio courses are essential elements of industrial design education(Mukherjee, 2021; Demirbilek, 2004). Students take these courses for 10 hours per week each semester, and these design studio courses aim to provide vocational training through practice. Students try to reflect on what they have learned about design in other required courses during their studio project. Each semester, students are expected to complete several design projects aimed at gaining different knowledge and skills as they progress through the design program. At the end of each project, the learning outcomes of the projects are evaluated and interpreted by an open jury composed of lecturers and practitioners or professionals.

First-year studio courses are reserved for Basic Design, in which the basic concepts of design are introduced; visual perception and creative thinking, abstract and conceptual applications, understanding basic material information, and evaluation of the given design problem from different perspectives. As a result of learning the basic design principles and design terminology in this studio course, students are expected to have a little difficulty understanding the information that the instructors will convey to them in the following studio courses and transferring them to their learning processes.

The second-year Industrial Design studio course projects are related to ergonomics, human-product interaction style and redesign. Design projects in this class focus on the functional requirements of products while encouraging systematic thinking and scenario creation. In the third year, Industrial Design studio projects often focus on questioning brand identity, product identity, system designs, designs covering new technologies and technological applications, innovation, user interaction, product language and aesthetics. Lastly, in the fourth year, design studio courses continue with a focus on collaborations with different sectors, including the design field. With this approach, it is aimed that our students rehearse their professional life before they graduate.

The topics discussed in the rest of the article are the fifth semester (third-year first semester) Industrial Design studio project structure and the student achievements targeted with this setup. The detailed studio course plan for the relevant term and the achievements aimed for the semester are explained below.

\section{Research Method}

To test the possible impact of different design approaches on design students' experience of designing brand identity-oriented products, a new course structure was implemented with fifteen students in the first product design studio of the third grade in the fall semester of 2020-2021. The studio course is structured (see Fig.1) for design students to design four different brand identity-oriented products with three different strategies defined according to the management and structure of the design process. This teaching strategy aims to raise more discussion about the methods/strategies used in the studio environment to design brand identity-focused products as trainers. 
Four instructors gave the design studio course together, all of whom are experts in product (industrial) design. There were fifteen students enrolled in the design studio course in the fall term of 2020, and they met twice a week for sixteen weeks. Each design studio course lasted five hours and was structured to design has been an important brand selection and filtering criterion. Students, each paired with a different brand, started with brand analysis research in six weeks and designed a new product with the visual identity of that brand. In the last project ( 7 weeks), the instructors determined two different products, an electric

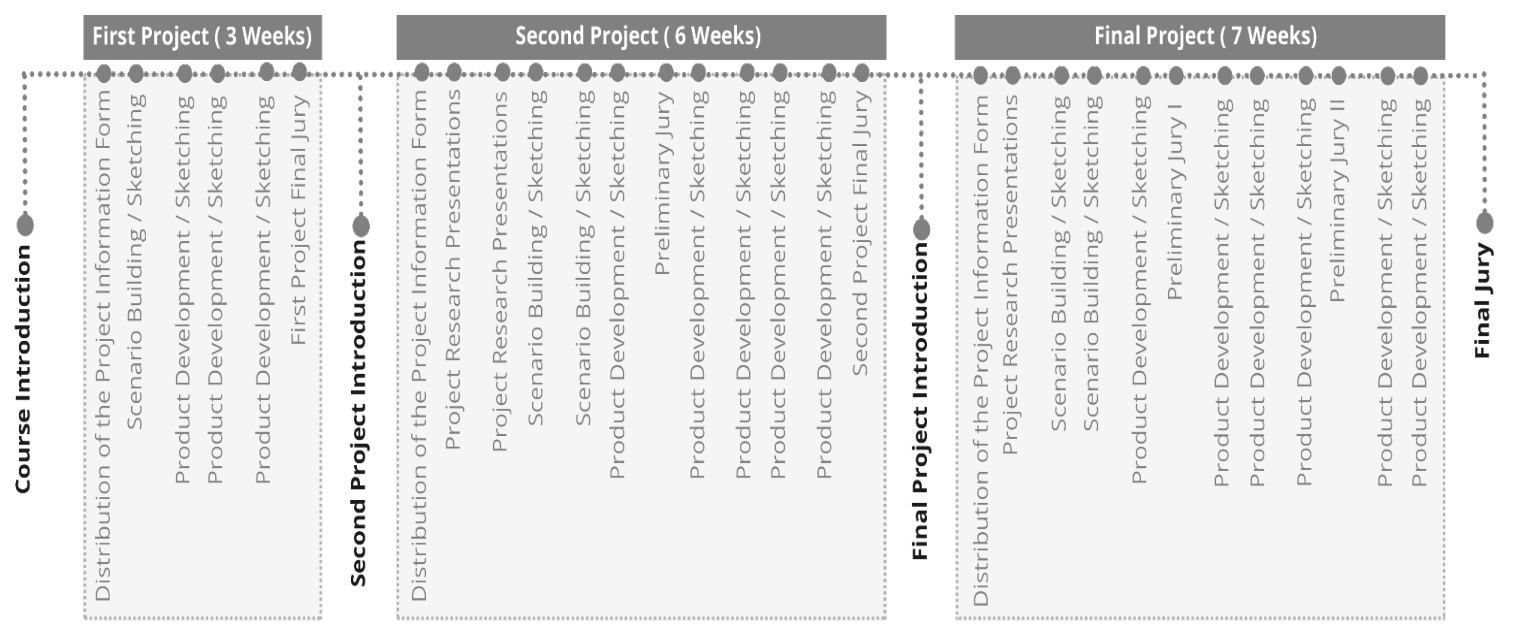

Figure 1: 2020-2021 fall- third-year first-semester design studio course structure

four different products (with two product options) by conducting three distinct brand identity focused design projects.

First of all, for the first project (the first three weeks), the students were asked to design a product that would fit a scenario that does not have a real-life counterpart. For this purpose, students analyzed the scenario and visual identity of a science fiction movie (TRON: Legacy) whose product design language is dominant. Subsequently, they designed different concept products with aesthetic concerns that would fit a design problem they determined, the fiction and design language of the movie.

In the second project (6 weeks), the course instructors determined fifteen different brands they used or encountered in real life, and each student was matched with a brand. In the brands selected for the second project, the chosen product that was designed was not being in the product range of the given brands toothbrush and shaver/epilation device, to design and form a product family of the same brand.

The data were collected through two main methods: participant observation and semistructured interviews. Throughout the semester, participant observation was used to observe the students' design process in the studio. During this process, field notes were taken. Semi-structured interviews were conducted with each student at the end of the semester, and each interview lasted 20 to 25 minutes.

The collected data were interpreted by comparing them with the field notes taken during the observations. Data analysis was done with an inductive and deductive approach to describe students' experiences with the three processes. In addition to data from observations and interviews, students' design solutions for each project were analyzed based on content and integrity. 


\section{Design Studio Project Processes and Evaluations}

As the first step to analyze the different design approaches applied in brand identity-oriented design projects, the students' design process in the third-year design studio was observed. To make appropriate inferences about the subject, it was aimed to document and observe the students' design processes and reveal the prominent results of the study. For this reason, firstly, the process outputs obtained from the observations, and then the results of the product design projects focused on brand identity are explicitly explained for the projects. The chapter ends with the discussion and evaluation of the findings of the project processes.

In this study, the design processes followed by the students in all three projects, sample design suggestions and observation outputs were shared. The projects and their output sequence is discussed in parallel with the design studio courses structure.

\subsection{Visual Identity Focused Design Projects (3 Weeks)}

The first project of the term was built on the concept of visual identity, which forms one of the foundations of the brand context for three weeks. The project process started with watching a science fiction movie, TRON: Legacy.

TRON: Legacy (Kosinski, 2011) was chosen for the first project due to it is being distinguished from other films in its genre with its design language and editing. In the making of the film, designers from different fields had worked collaboratively to create the visual image of the film (Kosinski et al., 2011). The reason behind starting the first project with a science fiction film focused on visual identity is to detach students from the realities of the world they live in, from the codes they know, and immerse them in a well-defined fictional universe.

After watching the movie, the students started to make sense of and analyze the visual language and technological infrastructure of this movie. In the first research sheets presented, it was seen that the students only used the screenshots they took from certain scenes of the movie without thinking much. To better understand and analyze the visual language of the film, the students were asked the reasons for choosing the products they have suggested to design during the design critiques. Thus, the instructors assisted them in deepening their analysis methods through different examples. After analyzing the visual language of the film, the outputs obtained from the analysis were visualized again with the help of freehand sketches and graphic programs and presented by the students.

In the presentations of the design proposals that came after the analysis of the film's visual language, it was observed that the students had difficulty in putting forward a product idea that fits the language and fiction of the film. The habits they have developed in the previous periods, the students left aside the analysis outputs they made about the visual language of the film and focused primarily on designing the physical products whose names they indicated. At this stage, the instructors who gave the course made the students question the relationship between the design suggestions they presented in the in-class critiques and the analyzes they made. It has been tried to explain how and in what way this aspect is missing in the design proposals.

During the three-week project period, the instructors criticized the students for how well the form of the product they designed was suitable for the visual and symbolic language of the film and how accurately it reflected the fictional and technological structure of the film. In addition, throughout the design process, it has been repeatedly observed that students have difficulties transferring the analysis outputs they have revealed during the research process to the idea development stage. The analysis skills demonstrated by the students during the project process were developed by criticizing them. As an example, as seen in Figure 2, products that fit the language and fiction of the film were designed. In addition, students' difficulties in transferring 


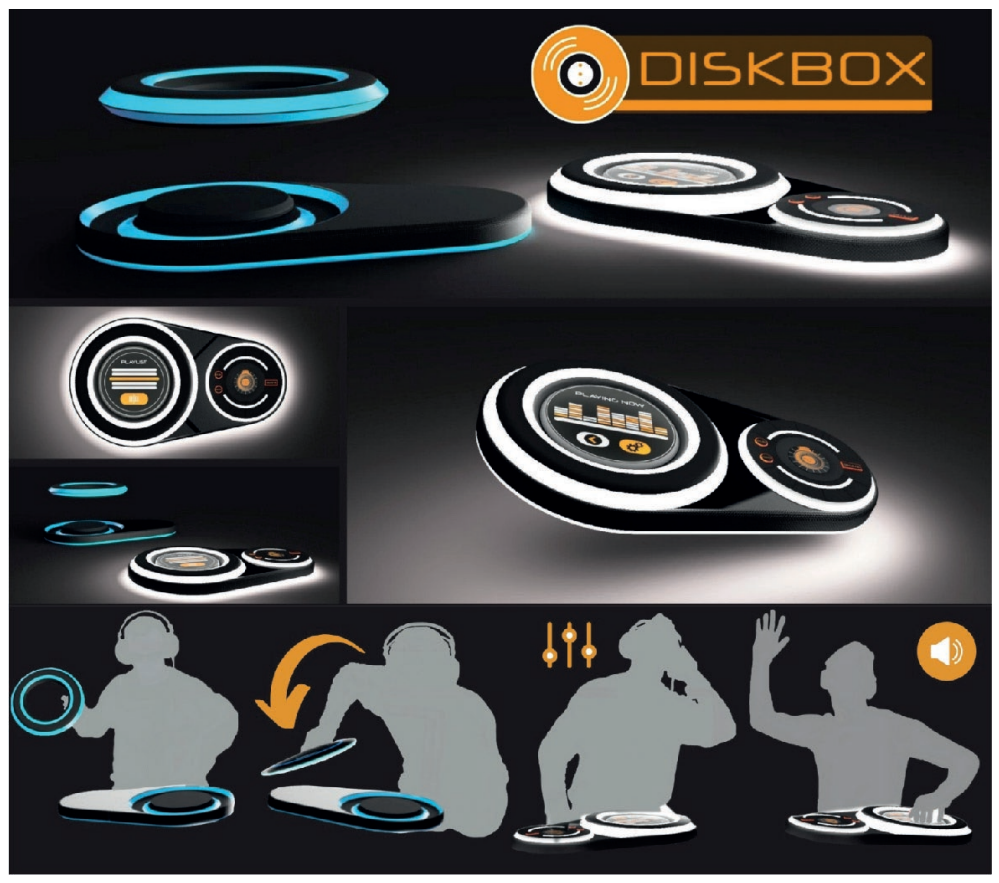

Figure 2. First Project Final Output (Student: Egehan Incecik, Product: DJ Setup)

knowledge and skills between studio course design processes negatively affected their project time management. A student supported this observation output in his interview as follows;

"... ... in fact, I couldn't decide which design proposal to advance. I thought all of the design suggestions that came to my mind were suitable for the film, you know... then, I thought, "now the time is running out, so I must choose one and start a design process". I actually decided at one point so that the design process could end."

In the process, time planning and product design skills reflecting the film's identity were developed, and at the end of the process, the students' ability to analyze, create and transfer visual identity through science fiction films developed. Thus, the ground was prepared to reinforce these skills in the second project with brand identity-oriented product design. Another student summarized this design project as follows;

"Let me open the movie to the point where I get stuck, watch the scenes that inspire me repeatedly, or design a product for which scene... It was fun for me to try to empathize by developing a project with a movie, with the characters in that universe. Overall, I can say that I enjoyed the process."

In the end, while commenting on the first project, the students emphasized that it was enjoyable to look at the movie frequently at the point where they get stuck and to try to empathize with the characters in that universe with a movie.

\subsection{Brand Identity Focused Design Projects (6 Weeks)}

In the second project, the students were expected to analyze the brand identity (visual identity, target user group) and the ability to transfer it to their product designs.

After three weeks, the second project started when the instructors decided on a hairdryer to be designed. Since the project aims to achieve a brand-focused design process, a hairdryer, a product with as few components as possible, was chosen to prevent students from concentrating on its details. In this way, the students have focused on the product-brand relationship. 
The course instructors determined fifteen brands that do not include hair dryers in their product range, then the students were matched with the brands by drawing lots, and the students' research process started. The reason for selecting a product that is not in the product range of brands is to prevent students from taking the applications of the brand on an existing product as a preliminary acceptance and producing a similar outcome. Thus, the students were expected to gain the ability to perceive the target user group of the brand, the symbolism used to communicate with this audience, and the visual reflections of this symbolism in the products of the brand, and to reflect what they perceive in the design of a different outcome.

There were deficiencies in transferring the analysis skills experienced in the first project to the second project. In the brand identity research, it was observed that, except for a few students, the students tried to understand and explain the brand without overthinking about the products belonging to the brands. The research tried to ensure that the brand analysis process progressed more accurately by guiding the students who included the areas that constitute the brand's identity, such as the area where the brand positions itself, its goals, and the target user group.
In the research phase of the project, after the students researched the brands and their target user groups, they started to design hair dryers independent of their brand's identity, as was experienced in the first project. Observing the repetition of the situation in both projects revealed a disconnection between the design process's research and idea development stages. In this case, the students had to be guided through the critiques to make identity analysis and reflect the analysis outputs. The students, who conducted the analysis phase well in the process and successfully transferred the brand's identity to the product design ideas, showed good progress by trying and eliminating many design proposal alternatives (Figure 3).

\section{"There is an imagination-oriented structure, but there is a product output that we embody. The transition there... I believe it was an exercise we had to do as designer candidates. I think it was beneficial."}

In the evaluation phase, the final product and the process that has been experienced are discussed in line with the expected acquisitions, as in the previous project. The brand analysis process, the outputs revealed in the process, the reflection of these outputs on the products, the consistency to the products'

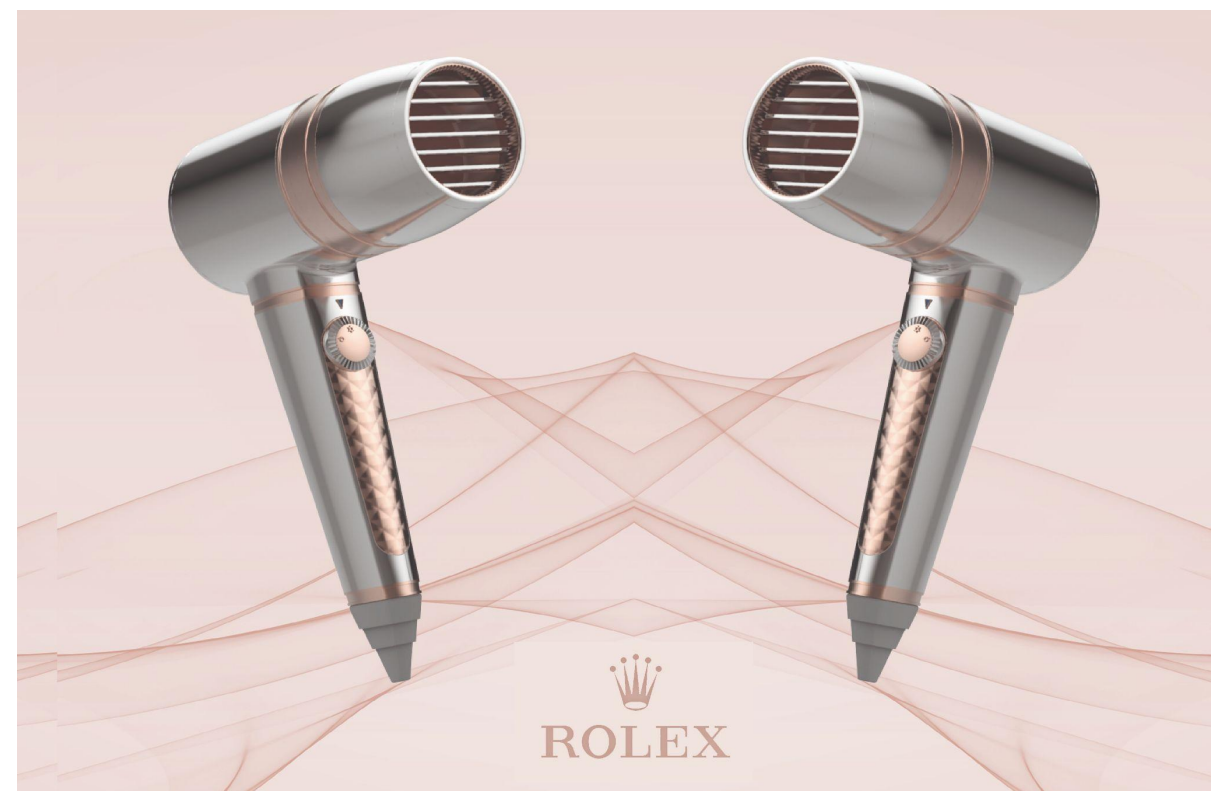

Figure 3. Second Project Final Output (Student: Ümithan Üçok, Product: Hairdryer for Rolex) 
functional context, and the manufacturability criteria are taken into consideration in the evaluation.

\subsection{Brand Identity Focused Product Family Design Projects (7 Weeks)}

In the seven-week final project of the term setup, it was aimed that the students understand the concept of product family on the knowledge and skills in the context of visual identity and brand identity, which they gained from the first and second projects. Thus, they achieved the ability to create product family unity in the focus of brand identity with the approach they display within the framework of this concept.

The project structure was carried out by designing two new products for the family of the relevant product without changing the brand and product that was worked on in the second project. In this way, students reinforce the related brand identity work with two new products and gain skills on product family design. One of the purposes of designing two new products in addition to the product designed in the previous project was to develop the other two products in the context of a product created by them after the concept of the product family was perceived. Another aim was to help students discover how this symbolism can be reflected in the product family and which approaches can be used alongside family unity.

The project started with the research and presentations made by the students in line with the analysis of the product family. In this project, it was observed that instead of examining the concept of family, the students included diverse product samples and carried out the research in this way. With the critiques, clues on how to conduct research on the concept of product family were given to the students, guidance was given in this direction, and it was seen that the students were able to reach the expected level of analysis.

The difficulty experienced in the transfer of the analysis phase to the idea development phase in the second project continued in this project. By continuing the habits they gained in the previous project courses, the students tried to develop individual products independent of the identity of the brands and the concept of family. This situation negatively affected the students' process management, making it difficult for them to transfer brand identity and

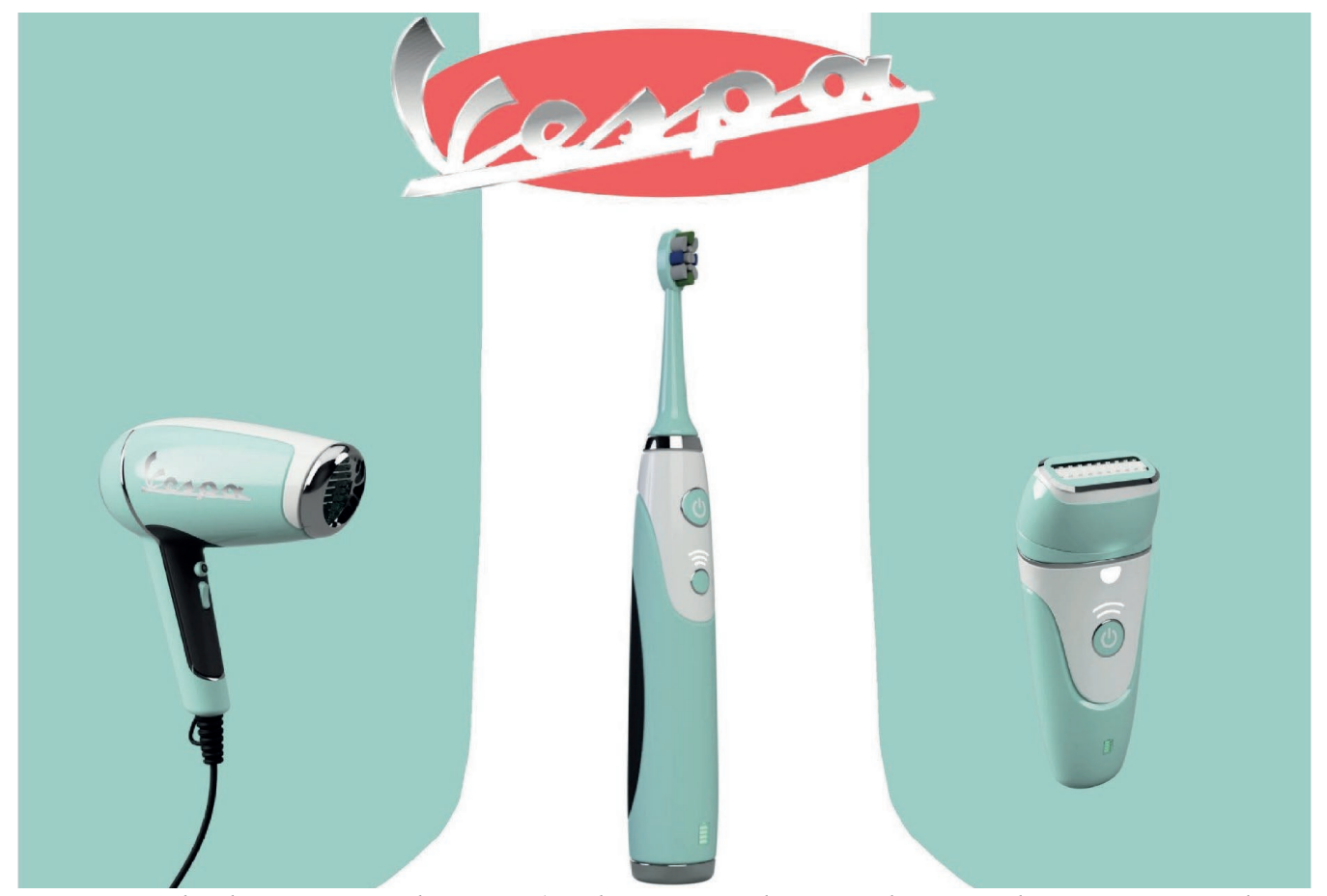

Figure 4. Third Project Final Output (Student: Bora Altay, Product Family: Hair Dryer-Electric Toothbrush-Hair Removal Tool for Vespa) 
product family analysis to their products, preventing them from developing different design proposals. The instructors of the design studio course guided the students with the questions they asked and the tips they gave, and they guided the students about process management. One of the remarkable observations is that the students tend to reconsider their product suggestions from scratch due to the received critiques. As a result, the students, who handled the analysis phase well, assimilated the family unity and made various attempts to transfer the brand identity and family concept to their products and achieved successful results. The students' comments about this project process reinforce that the objectives of the process have been achieved successfully.

"I felt like the designer of that brand for thirteen weeks..."

During the evaluation phase, the product designed in the second project was excluded from the evaluation as a grade. This stage was carried out on two products that were designed as a part of the product family. Evaluation criteria were how much the product family concept is perceived, how much the reflections of this concept is reflected in the designed products, and how much the brand identity can be read in new family members.

\subsection{Evaluation of Brand Identity Focused Design Projects in the Focus of Design Education}

An inductive coding technique was used to analyze the data collected from the semistructured interviews and participant observation. The codes obtained from the gathered data are illustrated in Figure 5 and tried to be explained by using direct quotations from the interviews. The analysis indicates that product design concepts that were appropriate for the brand's identity were scrutinized using the questions asked by the instructors during the design process. The findings also reveal that the instructors' questions and examples prompted students to explore, reflect, question, comprehend, and make sense of the relevance of knowledge.

During the fall semester, it was observed that students had difficulties in certain aspects while designing physical products with the focus of brand identity. The lecturers led the students to research, think, question, understand and make sense of the importance of knowledge and take responsibility with the questions they asked and the examples they gave during the design project processes. When students were not otherwise guided, they tended to begin straight to the design of their named physical product. However, in the end, the students succeeded in making brand and

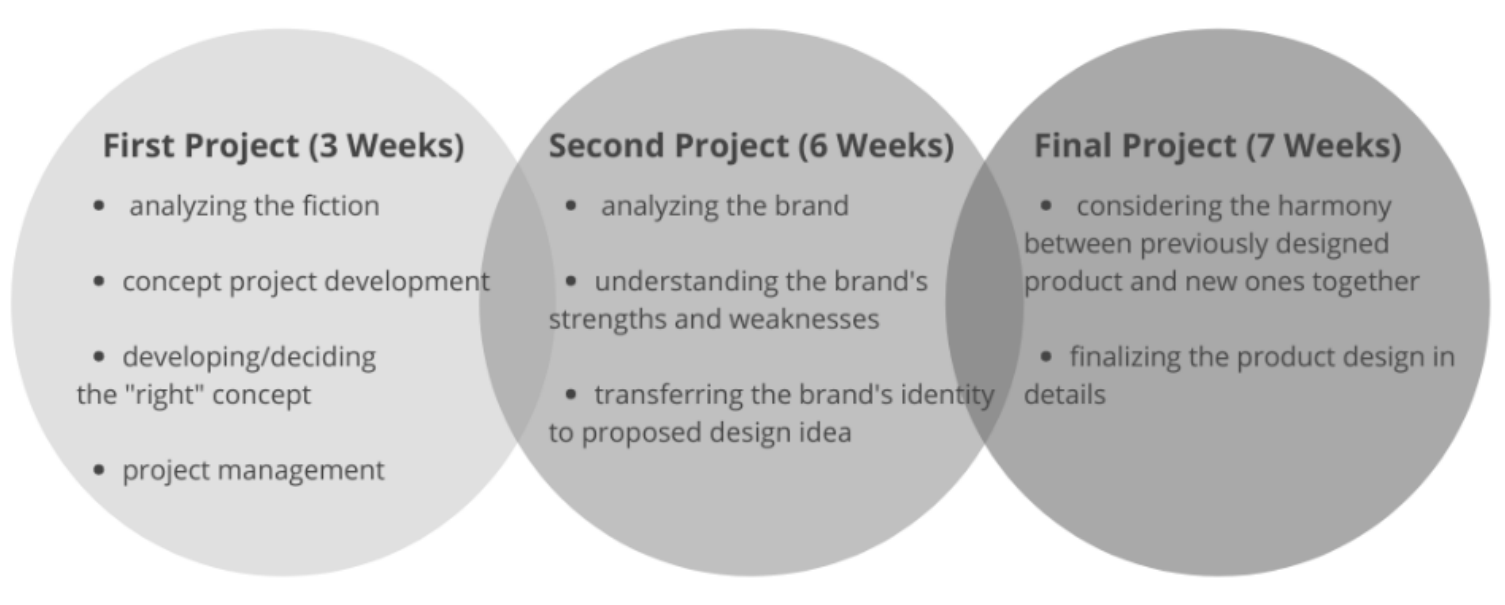

Figure 5. Repeated Comments from the Students' Evaluation of the Semester 
product analyses and obtaining design outputs suitable for the identity and character of the brand.

At the end of the semester, students made constructive comments about all three projects and, as designer candidates, shared the positive effects of this process on them with the following statement:

"This was a delightful process for me as well; this period may be my favourite period because you will always work in a brand... you will understand the identity of that brand and design a product belonging to that brand, to illustrate, if you work at Vestel, the product you design should reflect Vestel's general product language, or even when you establish your brand in the future, you will still have to have a brand identity, and you will have to develop it. In that sense, it was a process that I enjoyed."

In their interviews, the students chose the first project as they had the most difficulty with it while analyzing the semester. They mentioned the difficulty of designing a product that does not have a real-life counterpart and carrying out a project following the visual language of a world designed by others as their difficulty in the first project. Furthermore, the students said that the analysis of the science fiction film, which will prepare the ground for design decisions and determine the identity of their designs during the first project process, continued throughout the project process.

Unlike the first project, many students emphasized that the time allocated for research in the second project was sufficient, while a few students stated that this process continued until the last week of the project. Predominantly, after students researched brand identity and product identity, their efforts to develop product design ideas independent of brand identity and brand lines were followed in the idea development stage, leaving the research outputs aside. With this orientation, some design stages were repeated. Thus, in the second project, understanding and establishing the brand identity was the most important and challenging stage of the project according to the students. Unlike the first project, many students emphasized that the time allocated for research in this project was sufficient, while a few students stated that this process continued until the last week of the project.

They also expressed that they did not have experience with a similar project setup in their previous studio courses, therefore they had difficulty in analyzing a fiction prepared by others. Thus, the students underlined the outcomes of educators' observations by stating that the unsuccessful time and project management were indirectly caused by this inexperience.

The reasons for the difficulties mentioned by the students in the second project overlap with the observation results. The results of the interview data revealed that the students had problems in analyzing the brand identity and target audience of the brand. In addition, they mentioned that the symbolic analysis of the brand paired with them was considered idle time.

"My brand was a brand that I was not very familiar with. Since it's a brand topic that I don't know about and is out of my area of interest, I researched it even more deeply. That project improved my research thing quite a bit. It was an unfamiliar subject and a challenging project... I researched as much as I could. Whether it's visuality or production, it prompted me to research quite a bit. Also, since the brand did not have such a product, there was nothing I could take as an example. For example, when I typed premium hairdryer on the internet, almost nothing came out. That's why I devoted myself entirely to researching that brand. I researched the history of that brand, how they were made, what made it that brand... After learning these, I felt as if I had solved his algorithm. Things got more manageable for me later, but I had to change my mindset while researching; it forced me." 
On the other hand, one of the common comments for the second and final projects was that determining the production details of their design both challenged and excited them. The reason why it was interpreted as difficult was stated that the production methods and the material they chose did not match with the form they presented, so they had to make revisions by considering both contexts together in the process. These responses are reflected in the observations of the educators as they provided students with important feedback that guided their next design decisions, according to how close they had come to the identity of the brand assigned to them in their previous projects.

The results of the interviews showed the final project was the most straightforward project. During this project, the students were able to use the knowledge and skills they gained in the first two projects in the last project.

\footnotetext{
"Here it was easier as it was like a continuation of the second project. First, we researched the product family. The brands always have a product family. I researched what I could make a product family with the product I designed and what I could use in common. I progressed by building on the previous one; it was not difficult because we laid the foundation before."
}

According to the students, this semester's structure encouraged them to generate design ideas that are transferred for the appropriate user group and products to which wellanalyzed and understood under the assigned brand's identity. Thus, most of the students stated that they understood that even designing a product family can be a design problem. In addition to this, it has been expressed as quite challenging to establish common lines between different products that fall under the same brand's identity.

Overall, students described their semester experience of brand-focused design projects as excessively illuminating for their future experience. Some students frequently used adjectives such as "enjoyable" and "educative" in their interviews. All students stated that they understood what kind of design process awaits them in the future, as a result of this semester's structure.

\section{Conclusion and Discussion}

When the existing studies were examined, it was seen that there are design studio course setups focused on training industrial design students for the product design sector (Egan, 2021; Parmentier et al., 2021; Swanson, 2020; Meyer and Norman, 2020; Redström, 2020; Frascara, 2020). This article aims to discuss the importance of designing with a focus on brand identity and sharing the findings from a one-term experiment and practice in the design studio course. For this reason, it has been examined how the knowledge and skills defined during a semester are handled in the structuring of a brand identity focused studio course.

As mentioned in the article's introduction, different product design stimuli such as a brand's perception of identity, various visual form elements or colours are processed at different stages of the perception process (Slade-Brooking, 2016; Warell, 2015; Karjalainen and Snelders, 2010; Karjalainen, 2003b). Among the three design process setups implemented for 14 weeks, it was preferred by the lecturers to design a new product by reflecting the brand identity to the design proposals simultaneously from the idea development stage. In product design projects focused on brand identity, since the needs and habits of the user group include a mixture of the symbolic and functional components of the product, it is necessary for students to understand the perception of form-brand association and how design is based on this.

According to Warell (2015), consumers who are aware of two products of a particular brand can imagine what the third one looks like with the help of the brand's visual identity. It is also stated that a brand can be defined as forming its identity using the design of its products, occurring through symbolic, indexical or symbolic sign references (Warell,2015; 
Stompff, 2010). For example, similar visual form elements or design cues are consistently transferred to product designs, creating brand recognition. In contrast, brand or product associations such as sportiness are created through symbolic references in designs (Warell,2015;Stompff，2010; Karjalainen \& Snelders, 2010).

The specific experience in this design studio course is based on a practice in the studio with a limited number of students. Although the small number of students is an advantage to better interact with each student, repeating these practices with larger groups in the future will yield different results. Also, in the future, it may be more valuable to ask students to reflect on their design process throughout the semester and to collect data by helping them keep design diaries throughout the process. Product design studios' primary motivation and aim will be to enable students to think for themselves, question, learn to access information, and reach the product by internalizing the design processes while working on projects.

\section{References}

Demirbilek, O. (2004). Motivating students in research oriented courses in industrial design. In DS 33: Proceedings of E\&PDE 2004, the 7th International Conference on Engineering and Product Design Education, Delft, the Netherlands, 02.-03.09. 2004 (pp. 399-407).

Egan, A. (2021). Understanding Aesthetics in Design Education. In DS 110: Proceedings of the 23rd International Conference on Engineering and Product Design Education (E\&PDE 2021), VIA Design, VIA University in Herning, Denmark. 9th-10th September 2021.

Frascara, J. (2020). Design Education, Training, and the Broad Picture: Eight Experts Respond to a Few Questions. She Ji: The Journal of Design, Economics, and Innovation, 6(1), 106-117.

Greenberg, D., Ehrensperger, E., SchulteMecklenbeck, M., Hoyer, W. D., Zhang, Z. J., \& Krohmer, H. (2020). The role of brand prominence and extravagance of product design in luxury brand building: What drives consumers' preferences for loud versus quiet luxury? Journal of Brand Management, 27(2), 195-210. https://doi.org/10.1057/s41262-01900175-5

Heitmann, M., Landwehr, J. R., Schreiner, T. F., \& van Heerde, H. J. (2020). Leveraging Brand Equity for Effective Visual Product Design. Journal of Marketing Research, 57(2), 257-277.

https://doi.org/10.1177/0022243720904004

Homburg, C., Schwemmle, M., \& Kuehnl, C. (2015). New product design: Concept, measurement, and consequences. Journal of Marketing, 79(3), 41-56. https://doi.org/10.1509/jm.14.0199

Hsu, C. L., Chen, Y. C., Yang, T. N., Lin, W. K., \& Liu, Y. H. (2018). Does product design matter? Exploring its influences in consumers' psychological responses and brand loyalty. Information Technology and People, 31(3), 886-907. https://doi.org/10.1108/ITP-07-2017$\underline{0206}$

Karjalainen, T. M., \& Snelders, D. (2010). Designing visual recognition for the brand. Journal of Product Innovation Management, 27(1), 6-22.

Karjalainen, T. M. (2003, June). Strategic design language-transforming brand identity into product design elements. In Proceedings of the 10th International Product Development Management Conference,(págs. 1-16). Brussels.

Karjalainen, T. M. (2003, October). Strategic brand identity and symbolic design cues. In 6 th Asian design conference (pp. 1-13).

Kosinski, J., Bridges, J., Hedlund, G., \& Wilde, O. (2011). Tron Legacy. Walt Disney Studios Home Entertainment.

Kreuzbauer, R., \& Malter, A. J. (2007). Product design perception and brand 


\section{Journal of \\ Design Studio}

$\mathrm{v}: 3 \mathrm{n}: 2$ December 2021

categorization. Advances in Consumer Research, 34, 240-246.

Maurya, U. K., \& Mishra, P. (2012). What is a brand? A Perspective on Brand Meaning. European Journal of Business and Management, 4(3), 122-133.

Meyer, M. W., \& Norman, D. (2020). Changing design education for the $21 \mathrm{st}$ century. She Ji: The Journal of Design, Economics, and Innovation, 6(1), 13-49.

Mukherjee, S. K. (2021). Product Design with Form, Strength, and Function for Undergraduate Product Design Students-A Case Study. In Design for Tomorrow-Volume 2 (pp. 229-241). Springer, Singapore.

Naletelich, K., \& Spears, N. (2020). Analogical reasoning and regulatory focus: using the creative process to enhance consumer-brand outcomes within a co-creation context. European Journal of Marketing.

Oswald, D. (2010). Towards a redefinition of product design and product design education. In DS 62: Proceedings of E\&PDE 2010, the 12th International Conference on Engineering and Product Design Education-When Design Education and Design Research meet..., Trondheim, Norway, 02.-03.09. 2010.

Page, C., \& Herr, P. M. (2002). An investigation of the processes by which product design and brand strength interact to determine initial affect and quality judgments. Journal of Consumer Psychology, 12(2), 133147.

https://doi.org/10.1207/153276602760078668

Parmentier, D. D., Van Acker, B. B., Saldien, J., \& Detand, J. (2021). A framework to design for meaning: insights on use, practicality and added value within a project-based learning context. International Journal of Technology and Design Education, 31(4), 815-838

Redström, J. (2020). Certain uncertainties and the design of design education. She Ji: The
Journal of Design, Economics, and Innovation, $6(1), 83-100$.

Slade-Brooking, C. (2016). Creating a brand identity: a guide for designers. Hachette UK.

Stompff, G. (2010). The forgotten bond: Brand identity and product design. Design Management Journal (Former Series), 14(1), 26-32. https://doi.org/10.1111/j.19487169.2003.tb00336.x

Swanson, G. (2020). Educating the Designer of 2025. She Ji: The Journal of Design, Economics, and Innovation, 6(1), 101-105.

Wang, H. X., Chen, J., Hu, Y. C., \& Ye, M. (2008). The consistency of product design and brand image. 9th International Conference on Computer-Aided Industrial Design and Conceptual Design: Multicultural Creation and Design - CAIDCD 2008, 1142-1144. https://doi.org/10.1109/CAIDCD.2008.473076 $\underline{4}$

Warell, A. (2015). Identity references in product design: An approach for inter-relating visual product experience and brand value representation. Procedia Manufacturing, 3, 2118-2125. 